\title{
Músculo Romboides Supraescapular de la Llama (Lama glama)
}

\author{
Rhomboideus Suprascapularis Muscle of the Llama (Lama glama) \\ Carlos Alberto Arzone; Gabriel Alejandro Sánchez; Marcelo Acerbo; \\ Carlos Jorge Blanco; Fernando Carlos Pellegrino \& Ramiro Vidal Figueredo
}

\begin{abstract}
ARZONE, C. A.; SÁNCHEZ, G. A.; ACERBO, M.; BLANCO, C. J.; PELLEGRINO, F. C. \& VIDAL FIGUEREDO, R. Músculo romboides supraescapular de la llama (Lama glama). Int. J. Morphol., 27(2):403-406, 2009.

RESUMEN: El músculo romboides (m. rhomboideus) forma parte de la sinsarcosis que une la cintura del miembro torácico con el esqueleto axil en los mamíferos domésticos. En estas especies, está integrado por los músculos romboides cervical ( $m$. rhomboideus cervicis) y romboides torácico ( $m$. rhomboideus thoracis), siendo imposible establecer el límite entre ellos, a diferencia de lo que sucede en el Hombre. Los carnívoros en general, el cerdo y el conejo presentan, además de las partes mencionadas, el músculo romboides de la cabeza ( $m$. rhomboideus capitis). En la llama, la porción cefálica está ausente y la cervical pobremente desarrollada. Los autores proponen sumar a las porciones cervical y torácica del músculo romboides de este camélido sudamericano, al músculo romboides supraescapular ( $m$. rhomboideus suprsacapularis), descrito por Lesbre (1903), en el camello y el dromedario. En este trabajo se establecen las inserciones, dimensiones e inervación del músculo romboides supraescapular de la llama, elementos que permiten definirlo como otra porción del complejo muscular romboideo en dicha especie. Además, se postula su acción como elevador de la escápula, dirigiéndola craneal y dorsalmente.
\end{abstract}

PALABRAS CLAVE: Músculo romboides; Anatomía veterinaria; Camélidos sudamericanos; Llama.

\section{INTRODUCCIÓN}

El músculo romboides ( $m$. rhomboideus) forma parte del grupo muscular (músculos comunes o extrínsecos) que une la cintura del miembro torácico con el esqueleto axil (sinsarcosis escapulotorácica). En su composición más completa, este músculo posee tres partes o porciones, las cuales no están presentes en todas las especies.

La bibliografía sobre el músculo romboides es extensa. A continuación se reseñan las descripciones de diferentes autores sobre la disposición del mismo, tanto en el Hombre como en las especies domésticas y no tradicionales. Las mismas se tomarán como base para la caracterización y discusión sobre el músculo romboides suprescapular (M. rhomboideus suprascapularis) de la llama.

Barone (1980) afirma que el músculo romboides comprende en el Hombre una parte cervical y una torácica, completamente separadas. Las mismas son descriptas como dos músculos distintos, el romboides cervical (M. rhomboideus cervicis), más reducido y delgado, y el romboides torácico (M. rhomboideus thoracis). Refiere también que en todos los mamíferos domésticos, por el contrario, ambas partes se con- funden y el músculo romboides cervical es más carnoso y extendido que su par torácico, existiendo además en cierto número de especies (carnívoros, conejo y porcinos) una parte que se inserta en el occipital y constituye un músculo romboides de la cabeza ( $m$. rhomboideus capitis), más o menos aislable.

Para este autor, las inserciones de origen se verifican para el romboides de la cabeza, en la protuberancia occipital externa o la cresta nucal; para el romboides cervical, en la parte funicular del ligamento nucal y para el romboides torácico, en el ligamento supraespinoso y los extremos de los procesos espinosos torácicos, hasta la quinta (en Hombre y porcino), sexta (équidos) o séptima vértebra (rumiantes, carnívoros, conejo). La terminación se lleva a cabo en la cara medial del borde dorsal de la escápula en el hombre y los carnívoros, y se extiende ampliamente sobre la parte adyacente del cartílago que prolonga a la escápula, en los ungulados y el conejo.

Entre las funciones del músculo, considera que el mismo eleva la escápula y hace bascular su borde dorsal en direc- 
ción craneal. Agrega que, cuando el punto fijo es en la espalda, las partes cervical y craneana concurren a enderezar el cuello, al tirar sobre la cuerda del ligamento nucal y extender la cabeza, y que este rol se halla muy desdibujado en la estación erguida, lo cual se traduce en la debilidad del romboides cervical en el Hombre. En cuanto a los vasos y nervios, señala que la sangre es aportada por arterias variables, según las especies: costocervical, cervical profunda, vertebral y las primeras intercostales. La inervación es aportada por las ramas dorsales de los nervios cervicales y por una rama especial del plexo braquial (nervio del músculo romboides).

Las descripciones de Getty (1975) no difieren sustancialmente de las de Barone, en cuanto a orígenes e inserciones musculares y aportan los siguientes datos:

En el caballo, la porción torácica del músculo se origina de los procesos espinosos dorsales mediante el ligamento dorsoescapular. La acción del músculo consiste dirigir la escápula dorsal y cranealmente; cuando el miembro está fijo, la parte cervical eleva el cuello. La irrigación está a cargo del tronco costocervical y la artera cervical profunda. La inervación la proveen los nervios VI y VII cervicales y las ramas dorsales de los nervios espinales torácicos.

En los rumiantes no existe una división definida en músculos cervical y torácico, aunque por conveniencia se reconozcan frecuentemente dos partes. La porción torácica lleva la escápula dorsal y medialmente y contribuye a sostener el miembro cuando éste está en movimiento. La parte cervical contribuye a dirigir la escápula dorsal y cranealmente cuando el cuello está fijo; cuando actúa sólo un músculo, inclina el cuello lateralmente y se eleva cuando actúa junto con el músculo contralateral. La irrigación está dada por ramas de la arteria cervical profunda y escapular dorsal. La inervación la determinan ramas de los nervios cervicales y torácicos.

En su caracterización del músculo romboides del canino, Evans (1979) menciona la dificultad de separar las partes cervical y torácica, que aparecen íntimamente unidas. Señala, además, la presencia de la porción cefálica, $M$. rhomboideus capitis, que se deriva como un músculo acintado desde la porción cervical hacia el hueso occipital. Para este autor, la acción general del músculo consiste en elevar el miembro y traccionarlo junto con la espalda hacia craneal o hacia caudal. También, acercar la espalda contra el tronco (en común con todos los músculos extrínsecos). En su opinión, la inervación está dada por las ramas dorsales de los nervios cervicales y torácicos.

En una extensa descripción sobre el músculo que nos ocupa, Grassè (1971) establece homologías con los tetrápodos inferiores y lo caracteriza como hiposomático. Reconoce que las partes cervical y dorsal están inervadas por un nervio propio, el escapular dorsal ( $N$. dorsalis scapularis), rama colateral del plexo braquial, cuyo origen más frecuente es $\mathrm{C} 5$, y que, en sus porciones craneales, recibe ramas externas del plexo braquial.

Cuando compara el grado de independencia de las tres porciones del romboides en los distintos órdenes de mamíferos, Grassè destaca que:

Están totalmente confundidas en una capa única en el hipopótamo, los suidos, muchos marsupiales y roedores, así como en gran parte de los carnívoros.

El romboides de la cabeza está separado, mientras que el romboides cervical y del dorso permanecen unidos, en los mustélidos y en la mayoría de los primates. El romboides de la cabeza está ausente y los otros dos fusionados en los antropomorfos, artiodáctilos y perisodáctilos.

Con respecto a la participación de este músculo en la constitución de especializaciones en la región de la cruz, Grassè señala que en el cebú (Bos indicus), contrariamente a los camélidos en los cuales las jorobas no son más que elevaciones grasas sin contribución muscular, la giba está formada esencialmente por el músculo romboides cervical remarcablemente desarrollado y fuerte, poco unido al esqueleto axial y con un origen muy caudal (T2 a T4). A pesar de esto, se conserva la denominación "cervical" para diferenciarla de la dorsal, de origen más caudal. En el caso del bisonte, el romboides cervical también se desarrolla notablemente, pero en este caso parece ser una adaptación locomotora, ya que otros muchos músculos contribuyen a formar la giba.

Para Lesbre (1903), la porción cervical del romboides forma una punta bastante corta, un poco más aislada de los músculos vecinos hacia la parte superior de la espalda. La particularidad más remarcable de este músculo, según este autor, consiste en su clivaje en la parte caudal, de la cual resulta un nuevo músculo que pasa por encima del cartílago de la escápula, para insertarse en la cara externa del ángulo dorsal del hueso, y al que él propone llamar romboides supraescapular.

Por último, Smutz \& Bezuidenhout (1987) mencionan que el romboides del dromedario está representado por una bien desarrollada parte torácica y un fascículo simple representante del músculo romboides cervical. Agregan que este último se origina a través de la fascia a nivel de la línea mediana dorsal del cuello y se inserta en los dos tercios craneales de la cara medial del cartílago escapular, fusionándose ventralmente con la parte cervical del $\mathrm{m}$. serrato ventral. Para estos autores el $\mathrm{m}$. romboides torácico consiste en dos partes. La superficial es un músculo dispuesto en abanico, cubierto 
por la aponeurosis del m. dorsal ancho y la parte torácica del m. trapecio; se origina en el ligamento supraespinoso sobre las vértebras T3-6, y se inserta sobre la cara lateral de la parte caudal del cartílago escapular. La parte profunda se origina en el ligamento nucal sobre las primeras dos vértebras torácicas y se inserta principalmente sobre la superficie medial del cartílago escapular fusionándose con el $\mathrm{m}$. serrato ventral.

\section{MATERIAL Y MÉTODO}

Se disecaron diez llamas adultas de aptitud lanera, siete machos y tres hembras, exentas de patologías en la región en estudio. Cuatro de los ejemplares murieron naturalmente; el resto eran animales destinados a refugar debido a diferentes patologías y se los sometió a eutanasia bajo el siguiente protocolo:

1. Premedicaión con Xilazina, a dosis usuales por vía intramuscular.

2. Anestesia parenteral intravenosa con Tiopental sódico.

3. Sangrado "a blanco" mediante canalización de la arteria carótida común.

4. Inyección intraarterial de los cadáveres con soluciones conservantes.

En la disección propiamente dicha, se utilizaron técnicas e instrumental de rutina. En un primer paso se establecieron por palpación las estructuras anatómicas que sirvieron como puntos de referencia en las disecciones: el cartílago escapular, la espina y borde craneal de la escápula, la línea tricipital y la línea media dorsal.

Se expusieron los diferentes planos partiendo de los siguientes cortes:

- Ventral, de dirección craneocaudal, ubicado a nivel de la articulación humeral.

- Craneal, comienza en el corte anterior, paralelo al borde del músculo supraespinoso, en dirección ventrodorsal, hasta alcanzar la línea media dorsal.

- Caudal, desde el corte distal, con dirección ventrodorsal, siguiendo la línea tricipital hasta la línea media dorsal.

\section{RESULTADOS}

A continuación se describen los planos de la disección: Primer plano, formado por la piel; segundo plano, constituido esencialmente por la fascia omobraquial infiltrada en tejido adiposo; tercer plano, formado por una fascia resistente, que permite formar una capa; cuarto plano, constituido en su mayor parte la musculatura extrínseca de la cintura y miembro torácico. En él se reconocen los músculos trapecio, omotransverso, dorsal ancho y braquiocefálico. Entre los músculos propios del miembro se aprecia la cabeza larga del músculo tríceps braquial. Para exponer el quinto plano se seccionó transversalmente el músculo dorsal ancho a unos $15 \mathrm{~cm}$ en caudal de la línea tricipital. Posteriormente, se seccionó el músculo trapecio continuando la línea anterior, pero de forma curva, de concavidad ventral, a unos 3 o $4 \mathrm{~cm}$. por ventral de los orígenes de este músculo en los ligamentos nucal y supraespinoso. De esta forma ,la mayor parte del músculo queda insertado en la espina de la escápula, hacia donde se desplazó el muñón distal. Quinto plano, formado por el músculo que se denominará de ahora en más, romboides supraescapular. El mismo aparece como un músculo plano, triangular con la base dirigida dorsalmente; es en su mayor parte carnoso, excepto cerca de su origen donde se presentan bandas correspondientes a una aponeurosis nacarada. En su trayecto cubre por completo el cartílago escapular. Su cara superficial está cubierta por una delgada fascia, continuación de aquella de la región toracolumbar, que le da origen al músculo dorsal ancho.

El músculo tiene origen en el ligamento supraespinoso y a través de él en los extremos de las apófisis espinosas, de la $3^{\mathrm{a}}$ o $4^{\mathrm{a}}$ vértebra dorsal, hasta la $7^{\mathrm{a}}$ u $8^{\mathrm{a}}$. Desde allí se dirige ventralmente para insertarse en el ángulo caudal de la escápula, compartiendo esta inserción con la terminación del músculo serrato ventral en su porción torácica, que se observa claramente en medial del citado ángulo. Cuando se secciona transversalmente el músculo descrito, aproximadamente en su mitad, y se desplazan los muñones dorsal y ventralmente, queda al descubierto una fuerte fascia, con el mismo origen que la parte carnosa, pero con inserción en la superficie medial del cartílago escapular. Retirando la capa anterior se halla el músculo romboides torácico, enteramente carnoso, corto y ancho, con origen en el ligamento supraespinoso desde la $2^{\mathrm{a}}$ o $3^{\mathrm{a}}$ apófisis espinosa torácica hasta la $5^{\mathrm{a}}$ o $6^{\mathrm{a}}$, insertándose, luego de un pequeño recorrido oblicuo, en la superficie medial del cartílago escapular. En el borde craneal del romboides torácico, y unido a él muy laxamente, se encuentra un pequeño fascículo carnoso, con origen en el comienzo de la porción funicular del ligamento nucal y ventralmente adherido a la masa principal del músculo, con el cual se inserta.

La inervación del romboides supraescapular y la porción torácica convencional proviene del nervio escapular dorsal o dorsal de la escápula, el cual es parte del plexo braquial. Desde su origen, el nervio se dirige dorsalmente en relación a la superficie lateral del músculo serrato ventral, parte cervical, al cual perfora para seguir ascendiendo por la cara profunda de dicho músculo. Una vez que supera el borde dorsal del serrato, emite ramas para la porción torácica del romboides y se hace superficial sobre el borde craneal del romboides supraescapular, donde finaliza cerca de la mitad de su cara lateral. 


\section{DISCUSIÓN}

Es Lesbre quien denomina a este músculo romboides supraescapular en el camello bactriano y el dromedario. Smuts \& Bezuidenhout describen al músculo en el dromedario, al que denomina porción superficial del romboides torácico. Si bien ambos autores plantean la existencia del músculo en una especie muy relacionada taxonómicamente con la llama, ninguno de ellos establece las bases para determinar que el músculo pertenece al grupo del romboides y no mencionan al nervio escapular dorsal como el responsable de inervarlo.

Como se mencionó con anterioridad, la inervación del romboides supraescapular y de la porción torácica convencional proviene del nervio escapular dorsal, una rama derivada del plexo braquial destinada a los músculos serrato ventral y romboides. Schaller (1996) lo cita y agrega que, en general, este nervio no figura en los libros de texto de Anatomía Veterinaria. Por lo tanto, al ser parte del plexo braquial, este nervio es derivado de las ramas ventrales de los nervios espinales cervicales, permitiendo definir al músculo en estudio como hiposomático e integrante del músculo romboides. Dado que el músculo dorsal ancho, en la mayoría de las especies domésticas se dispone cubriendo lateralmente una parte del cartílago escapular, podría inferirse que el músculo que nos ocupa es una parte del mismo que en la llama migró su inserción alcanzando el ángulo caudal de la escápula. Sin embargo, la inervación que se ha demostrado por disección en este trabajo no avala dicha inferencia.

La fascia que cubre la cara medial del músculo en estudio puede homologarse al ligamento dorsoescapular medial del equino, con el que comparte el origen pero difiere en su inserción, que se realiza en la superficie medial del cartílago escapular.

El pequeño fascículo craneal unido al romboides torácico evidenciado en las disecciones, representaría al romboides cervical. En realidad, la existencia de esta porción es discutible, ya que no existe convención acerca del punto en el que finaliza el ligamento supraespinoso y comienza la porción funicular del ligamento nucal en la llama.

En cuanto a las funciones del músculo romboides supraescapular, por su origen, inserción y estructura, serían sostén y fijación del cinturón torácico. Además, actúa como antagónico a la acción del músculo serrato ventral torácico. Este último es un poderoso transmisor del peso corporal hacia la cintura torácica, lo que sumado a la importante inclinación caudal de la escápula en esta especie, tiende a la flexión de la articulación del hombro. El romboides supraescapular aparece como netamente opositor a esta acción.

ARZONE, C. A.; SÁNCHEZ, G. A.; ACERBO, M.; BLANCO, C. J.; PELLEGRINO, F. C. \& VIDAL FIGUEREDO, R. Músculo romboides supraescapular de la llama (Lama glama). Int. J. Morphol., 27(2):403-406, 2009.

SUMMARY: The rhomboideus muscle of the domestic mammals is part of the muscular set that joins the scapular waist to the axial skeleton. In these animals, the forenamed muscle has a cervical portion (m. rhomboideus cervicicis), and a thoracic portion ( $m$. rhomboideus thoracis). Unlike in the man, these parts cannot be separated. In addition, carnivores, pigs and rabbits also have a cephalic portion ( $m$. rhomboideus capitis). In the llamas, the cephalic portion is absent, and the cervical part is poorly developed. The authors propose to add a suprascapular portion (m. rhomboideus suparsacapularis), first described by Lesbre, 1903 in camels, to the Rhomboideus muscular complex of the llama. In this study, the authors describe the length, insertions, and inervation of the Rhomboideus Suprascapular muscle of the llama in order to define it as another portion of the Rhomboideus muscular complex. Moreover, the forenamed muscle is proposed as a scapular elevator.

KEY WORDS: Rhomboideus muscle; Veterinary anatomy; New World camelids; Llama.

\section{REFERENCIAS BILIOGRAFICAS}

Barone, R. Anatomie comparée des mamifères domestiques. $2^{\mathrm{a}}$ ed. Tome II: Arthrologie et Myologie. París, Éditions Vigots, 1980.

Evans, H. \& Christensen, G. Miller's Anatomy of the Dog. $2^{\text {nd }}$ ed. Philadelphia, Saunders, 1979.

Getty, R. Sisson and Grossmann's The Anatomy of the Domestics Animals. $5^{\text {th }}$ Ed. Philadelphia, Saunders, 1975.

Grassè, P. Traité de Zoologie. Anatomie Systématique Biologie. Tome XVI. Fasc. II. París, Masson, 1971.

Lesbre, F. X. Recherches Anatomiques Sur les Camélidés. Anatomie du Chameaux a Deux Bosses; differences entre les deux especes de chameaux; differences entre les chameaux et les lamas. Lyon, Archives du Museum d'histoire naturelle de Lyon, 1903.

Schaller, O. Nomenclatura Anatómica Ilustrada. Zaragoza, Acribia, 1996.

Smuts, M. S. \& Bezuidenhout, A. J. Anatomy of the Dromadary. Oxford, Clarendon Press, 1987.

Dirección para correspondencia:

Carlos Alberto Arzone

Cátedra de Anatomía.

Facultad de Ciencias Veterinarias.

Universidad de Buenos Aires

Recibido : 24-09-2008

ARGENTINA
Aceptado: 13-01-2009 